\title{
EJNSO
}

\section{Effect of preincisional peritonsillar infiltration of bupivacaine on post-tonsillectomy pain}

\author{
Ahmed Gaber Abdel Raheem, Zaki Mohamed Farouk \\ Otorhinolaryngology Department, South Valley University Hospital, Qena, Egypt
}

\begin{abstract}
Background: Tonsillectomy is one of the most common surgeries in the world which is followed by severe post-operative pain. The concept of using bupivacaine as pre-emptive analgesic to minimize post-operative pain is a well-established by some surgeons. But the role of bupivacaine to decrease post tonsillectomy pain is still viewed with some degree of suspicion by other otolaryngologists.

Objective: To determine the effect of preincisional bupivacaine $0.25 \%$ infiltration on post-tonsillectomy pain.

Materials and Methods: A prospective, randomized control trial was performed during a period from June 2015 to November 2015, 60 patients who underwent tonsillectomy were divided into two equal groups. The first group (A): who received infiltration of bupivacaine, and the second group (B): who received placebo infiltration of saline. Pain scores were assessed postoperatively using a visual analogue scale (VAS) at 1, 4, 8 and 24 hours after the procedure .

Results: According to our statistical analysis and data, the reduction in pain at $1(\mathrm{P}=0.214)$ hour in group A was statistically insignificant compared with group B. However, at 4 $(\mathrm{P}=0.002), 8(\mathrm{P}=0.000)$, and $24(\mathrm{P}=0.001)$ hours post-operatively, the reduction of pain in group A was statistically significant compared with group B .

Conclusion: Injection of plain bupivacaine solution in a $0.25 \%$ concentration just 5 minutes before surgery appears to be effective in reducing post-tonsillectomy pain within the first 24 hours.
\end{abstract}

Keywords: Pain, Tonsillectomy, Bupivacaine.

\section{Introduction:}

Tonsillectomy is one of the most common surgeries in the world which is followed by severe post-operative pain. This pain affects feeding, increasing the period of resting before coming back to school or work. The advantages of decreasing the pain are shorter recovery period, lower risk of postoperative bleeding, shorter hospitalization stay, and returning to a normal dietary regimen and a status of activity which is appropriate for the patient and his/ her parents sooner (Nilesh, 2002).

A sore throat may persist for two weeks following surgery while postoperative pain may necessitate a hospital stay (Timby et al., 2006). Recovery can take up to 10 days and high liquid intake is very important during this time, since dehydration increases pain, leading to poor fluid intake (Pemberton et al., 1988). 
The role of local injection of analgesic drugs in tonsillectomy is of controversy.

The aim of our study was to evaluate the effect of local bupivacaine infiltration on decreasing pain after tonsillectomy.

\section{Patients and Methods:}

During the period from June 2015 to November 2015, 60 patients of both gender ( 29 males - 31 females), their ages ranged from 5 to 15 years with mean age 8.7 of physical status I according to American Society of Anesthesiologists [ASA], tonsillectomy was done for recurrent tonsillitis.

Exclusion criteria included known allergy to bupivacaine, patients with a history of previous disease or coagulation problems and peritonsillar abscess and conditions requiring surgery in addition to tonsillectomy e.g. adenotonsillitis, in order to reduce bias introduced from other potential sources of pain. All procedures and patient care were done at ENT department, Qena University Hospital.

Patients were divided into two groups, group (A) who received infiltration of bupivacaine and group (B) who received placebo infiltration of saline. All patients were fasted for 5-8 $\mathrm{h}$ before anesthesia. After inserting intravenous line with Ringer's solution and monitors (noninvasive blood pressure, ECG, and pulse oximeter for $\mathrm{SpO} 2$ ) were used.

Patients were randomly allocated into two groups with 30 patients in each group to receive either peritonsillar infiltration of bupivacaine (group A) or saline (group B). Patients received a standardized anesthetic technique that included induction with propofol (2-3 $\mathrm{mg} / \mathrm{kg}$ intravenously), and atracuim $\quad(0.5 \quad \mathrm{mg} / \mathrm{kg}$ intravenously) to facilitate endotracheal intubation with suitable sized cuffed tube. Fentanyl (1-2 $\mathrm{mg} / \mathrm{kg}$ ) was administered as an analgesic agent before infiltration.

Anesthesia was maintained with isoflurane in oxygen/air mixture. Patients were mechanically ventilated in ventilation parameter that maintained an end-tidal carbon dioxide (EtCO 2) around 30-35 mmHg. After endotracheal intubation, positioning and application of mouth gag, peritonsillar infiltration of $4 \mathrm{ml}$ of a solution of bupivacaine $0.25 \%$ in the case group and $4 \mathrm{ml}$ of normal saline in the control group was applied pericapsulary through the tonsillar bed and peritonsillar tissues in a fanwise direction from the superior to inferior poles of the fossa, using a prepared syringes after careful aspiration 3 minutes prior to the onset of surgery.

Tonsillectomies were performed using dissection and ligation technique by the same ENT surgeon. Any bleeding occurred during the procedure was controlled by suturing and ligation. At the end of the surgery, anesthesia was discontinued, and the residual effect of muscle relaxant was reversed with neostigmine $(0.04$ $\mathrm{mg} / \mathrm{kg})$ and atropine $(0.02 \mathrm{mg} / \mathrm{kg})$. The tracheal tube was removed in the lateral position and then oxygen was administered through a face mask to the patient.

After extubation, patients were shifted to the recovery room. In the interior part of ENT department, patients were kept at the hospital for 24 hours, antibiotic (ampicillin/sulbactam, $50 \mathrm{mg} / \mathrm{kg} /$ ) intravenously was administered to the patients.

Pain scores were assessed at 1, 4, 8, and 24 hours postoperatively using a visual analogue scale (VAS) scoring 1 to $10(1=$ no pain and $10=$ worst pain possible). Level of pain on full jaw opening ten hours after surgery was described as, (1) none, (2) mild, (3) 
moderate, (4) sever, (5) worst ever felt (Tyagi et al, 2012). Any intraoperative or post-operative complications as bleeding or infection were documented.

Patients discharged on the next postoperative day and prescribed Amoxicillin suspension and acetaminophen syrup for 10 days. Continuous monitoring of the patients after discharge was carried by their parents and follow up visits.

\section{Statistical analysis:}

The data was collected, revised, coded and entered to the Statistical Package for Social Science (SPSS) version 16; the qualitative data was presented as number and percentages and compared together using Chisquare test while the quantitative data was presented as mean, standard deviations and ranges and compared together using independent t-test. $\mathrm{P}$ value of $<0.05$ was considered statistically significant.

\section{Results:}

There were no statistically significant differences between the groups for sex, age, and indication for surgery.

Pain were assessed with a visual analogue scale (VAS) one, four, eight, and twenty-four hours postoperatively. For group $\mathrm{A}$, the results of the pain evaluation (Mean \pm SD) at 1 hour was $6.70 \pm 0.83$, at 4 hours was $5.37 \pm 1.27$, at 8 hours was $4.50 \pm 1.19$, and at 24 hours was $3.63 \pm 0.99$, while the results of group B at 1 hour was $6.97 \pm 0.80$, at 4 hours was $6.37 \pm 1.12$, at 8 hours was $5.36 \pm 1.06$, and at 24 hours was $4.57 \pm 1.10$ as shown in (Figure 1). The reduction in pain at $1(\mathrm{p}=0.214)$ hour in group $\mathrm{A}$ was statistically insignificant compared with group $\mathrm{B}$. However, at $4(\mathrm{P}=0.002), 8(\mathrm{P}=0.000)$, and $24 \quad(\mathrm{P}=0.001)$ hours postoperatively, the reduction of pain in group A was statistically significant compared with group B (table 1).

\begin{tabular}{|c|c|c|c|c|}
\hline \multirow{2}{*}{$\begin{array}{c}\text { Pain Score } \\
\text { P-value }\end{array}$} & \multicolumn{2}{|c|}{ Mean \pm SD } & \multirow{2}{*}{$\begin{array}{l}\text { P- } \\
\text { value }\end{array}$} & \multirow[t]{2}{*}{ Comment } \\
\hline & $\begin{array}{l}\text { Group (A) } \\
\text { Bupivacaine }\end{array}$ & $\begin{array}{l}\text { Group (B) } \\
\text { Placebo }\end{array}$ & & \\
\hline After $1 \mathrm{hr}$ & $6.70 \pm 0.83$ & $6.97 \pm 0.80$ & 0.214 & $\begin{array}{c}\text { Non- } \\
\text { Significant }\end{array}$ \\
\hline After $4 \mathrm{hr}$ & $5.37 \pm 1.27$ & $6.37 \pm 1.12$ & 0.002 & Significant \\
\hline After $8 \mathrm{hr}$ & $4.50 \pm 1.19$ & $5.36 \pm 1.06$ & 0.000 & Significant \\
\hline After $24 \mathrm{hr}$ & $3.63 \pm 0.99$ & $4.57 \pm 1.10$ & 0.001 & Significant \\
\hline
\end{tabular}

Table (1): Comparison between group (A) and group (B) as regard Postoperative mean Pain score.

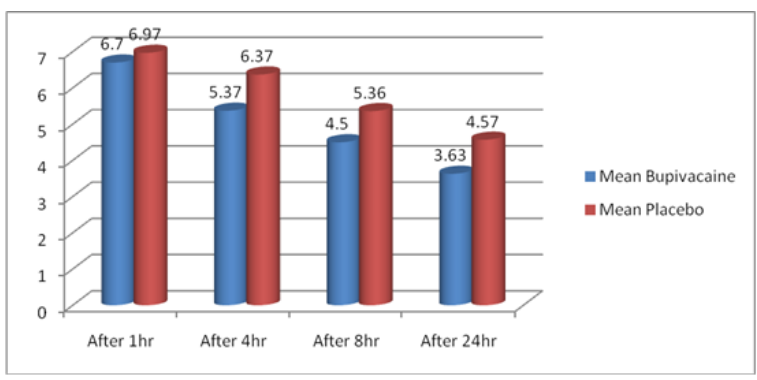

Figure (1): Comparison between group (A) and group (B) as regard Postoperative mean Pain score.

Pain on jaw opening at 10 hours after surgery: described as : (1) none, (2) mild, (3) moderate, (4) severe, (5) worst ever felt, we can say no patients in both groups have experienced severe pain on full jaw opening at 10 hours as shown in Figure (2) and there is significant difference was noted between the groups in level of pain on full jaw opening 10 hours after surgery $(\mathrm{P}=0.011)$ Table (2). 


\begin{tabular}{|c|c|c|c|}
\hline $\begin{array}{c}\text { Pain on full } \\
\text { jaw opening } \\
\text { at 10 hours }\end{array}$ & Mean \pm SD & $\begin{array}{c}\text { P- } \\
\text { Value }\end{array}$ & Comment \\
\cline { 1 - 2 } Group (A) & $\mathbf{2 . 2 0 \pm 0 . 5 5 1}$ & $\mathbf{0 . 0 1 1}$ & Significant \\
\cline { 1 - 2 } Group (B) & $\mathbf{2 . 6 0 \pm 0 . 6 2 1}$ & & \\
\hline
\end{tabular}

Table (2): mean pain score on full jaw opening at 10 hours after surgery in group(A) and $\operatorname{group}(\mathrm{B})$.

None of the patients were complicated by post-tonsillectomy bleeding, bupivacaine adverse effects or infection, all were discharged from the hospital on the next post-operative day, and all showed normal recovery during out-patient follow up.

\section{Discussion :}

Tonsillectomy is a commonly performed procedure in children. In the pediatric patient, postoperative pain results in poor fluid intake leading to dehydration with more throat pain. many attempts have been adopted to minimize the postoperative pain of tonsillectomy (Ohlms et al., 1995).

Pain is a subjective and complex expression (Garron et al., 1979).

Pain measurement depends on several variable factors like personal experience, social standard, perceptual abilities, anxiety level and the ability to express the pain type based on some reference frame (Schoem et al., 1993). It has been suggested that the postoperative pain after tonsillectomy is caused by nerve irritation, inflammatory process and muscles spasm. The pain subsides completely after the full mucosal coverage of muscles ,2: 3 weeks after surgery (Freeman et al., 1992).

The role of Bupivacaine is to inhibit stimulation of fiber-c afferent neurons decreasing stimulation of dorsal horn neurons of spinal cord. The effect of bupivacaine may last for up to 1 week after surgery because of pre-emptive analgesia mechanism (Nilesh, 2002).
The efficacy of bupivacaine in lowering pain after tonsillectomy is a controversy. So, several studies were done to demonstrate the effect of bupivacaine as a local analgesic on post-tonsillectomy pain. Our study showed that infiltration of $0.25 \%$ bupivacaine 5 minutes before tonsillectomy reduced the postoperative pain.

One hour post-operatively the pain reduction was not statistically significant; however, later at 4,8 , and 24 hours there was significant pain reduction. This may be explained as drowsy condition of patients in the early post-operative hours affects their ability of pain evaluation.

In our study the effect of bupivacaine seen subjectively was confirmed by full jaw opening at 10 hours after surgery. We agree with Strub et al (1996) who showed that local injection of bupivacaine reduces patient's pain during the first 24 hours after surgery. And agree with Johansen et al (1996) who conducted that injection of $5 \mathrm{ml}$ of $0.25 \%$ bupivacaine solution in the case group and equal amount of normal saline in the control group result in less pain and lower use of analgesics in the case group $(\mathrm{P}<0.001)$. And also agree with Alvarez et al (1997) who showed that bupivacaine is an effective drug in reducing the pain after tonsillectomy. And agree with Vasan et al (2002) who conducted a prospective doubleblind trial to evaluate pre-incision Bupivacaine infiltration compared with placebo in pain reduction for 10 days. They found that pre-dissection Bupivacaine infiltration reduces shortand long-term pain in children undergoing tonsillectomy. And agree with Grainger et al (2008) who published a systematic review and meta-analysis evaluating the usage of Bupivacaine in providing analgesia post tonsillectomy. 
They included 13 studies in their meta-analysis, and concluded that overall, either topical application or infiltration of Bupivacaine, can significantly reduce pain scores. Our study showed that an even lower concentration of Bupivacaine $(0.25 \%)$ was effective in providing post tonsillectomy analgesia. But we disagree with Unal et al (2007) who reported that Peritonsillar infiltration of bupivacaine is insufficient to control postoperative pain, it is more effective than ropivacaine for reducing postoperative analgesic requirement. Also, we disagree with Kountakis et al (2002) in this study 34 patients, injection of $10 \mathrm{ml}$ of 0.5 bupivacaine in the case group and $10 \mathrm{ml}$ of normal saline in the control group were performed.

There was no significant difference in post-operative pain between the two groups. Also, we disagree with Nordahl et al. (1999) who did not find a correlation between injection of bupivacaine and pain after tonsillectomy. And disagree with Moss et al (2011) who reported that lidocaine plus Bupivacaine compared with placebo, when used as a preincision injection, have no role in posttonsillectomy pain reduction.

And disagree with Schoem et al (1933) who found, Bupivacaine offered no advantage over placebo in the control of early postoperative pain following adult tonsillectomy. As described, there is equivocal effect of local anesthetics injections on reducing post-tonsillectomy pain.

In these studies, the sample size was small which may have a role in the controversy regarding the efficacy of bupivacaine as a local analgesic on post-tonsillectomy pain. As regard adverse effects of bupivacaine is an important parameter to be recorded. In our study no cases were recorded by bupivacaine injection complication.
But Bean-Lijewski (1997) reported two cases of upper airway obstruction following pre-tonsillar injection of bupivacaine.

He believed that very deep injection of this drug may be the cause resulting in blockage of recurrent laryngeal nerve and upper airway obstruction. Superficial submucosal injection of this drug diminishes this risk. And also, Fradis et al (1998) reported a deep cervical abscess and a brainstem stroke following simultaneous injection of epinephrine and bupivacaine.

\section{Conclusion:}

Bupivacaine is a safe and welltolerated local anesthetic. Injection of plain bupivacaine solution in a $0.25 \%$ concentration just 5 minutes before surgery appears to be effective in reducing post-tonsillectomy pain within the first 24 hours.

\section{Conflict of interest}

The authors declare no competing interests.

\section{Reference:}

1. Alvarez MG, Santaolalla BF, Cebrián JP, Aránguez GM, López MG, García FM. Intraoperative infiltration of $0.5 \%$ bupivacaine in pediatric tonsillectomy. Acta otorrinolaringologica espanola. 1997 May;48(4):287-90.

2. Bean-Lijewski JD. Glossopharyngeal nerve block for pain relief after pediatric tonsillectomy: retrospective analysis and two cases of lifethreatening upper airway obstruction from an interrupted trial. Anesthesia \& Analgesia. 1997 Jun 1;84(6):1232-8. 
3. Tyagi V, Pal KS, Garg D, De S, Nagpure PS. Control of postoperative pain with peritonsillar infiltration with bupivacaine $\quad 0.25 \%$ in tonsillectomy patient. Journal of pharmacology and biological science. 2012; 1:22-5.

4. Fradis M, Goldsher M, David JB, Podoshin L. Life-threatening deep cervical abscess after infiltration of the tonsillar bed for tonsillectomy. Ear, nose \& throat journal. 1998 May 1;77(5):418.

5. Freeman SB, Markwell JK. Sucralfate in alleviating post-tonsillectomy pain. The Laryngoscope. 1992 Nov;102(11):1242-6.

6. Garron DC, Leavitt F. Demographic and affective covariates of pain. Psychosomatic medicine. 1979 Nov.

7. Grainger J, Saravanappa N. Local anaesthetic for post-tonsillectomy pain: a systematic review and meta-analysis. Clinical Otolaryngology. 2008 Oct;33(5):411-9.

8. Johansen M, Harbo G, Ilium P. Preincisional infiltration with bupivacaine in tonsillectomy. Archives of OtolaryngologyHead \& Neck Surgery. 1996 Mar 1;122(3):261-3.

9. Kountakis SE. Effectiveness of perioperative bupivacaine infiltration in tonsillectomy patients. American journal of otolaryngology. 2002 Mar 1;23(2):76-80.

10. Schoem SR, Watkins GL, Kuhn JJ, Alburger JF, Kim KZ, Thompson DH. Control of early postoperative pain with bupivacaine in adult local tonsillectomy. Archives of Otolaryngology-Head \& Neck
Surgery. 1993 Mar 1;119(3):2923.

11. Moss JR, Cofer S, Hersey S, Goudy S, Werkhaven J, Swanson $\mathrm{E}$, et al. Comparison of clonidine, local anesthetics, and placebo for pain reduction in pediatric tonsillectomy. Arch Otolaryngol Head Neck Surg 2011; 137: 591-597.

12. Nilesh R. Preincisional bupivacaine in tonsillectomy pain relief. Arch Otolaryngol head and neck surg 2002; 128 : 144-9.

13. Nordahl SH, Albrektsen G, Guttormsen AB, Pedersen IL, Breidablikk HJ. Effect of bupivacaine on pain after tonsillectomy: a randomized clinical trial. Acta Otolaryngol 1999; 119 (3): 369- 76.

14. Ohlms, L.A., R.T. Wilder and B. Weston, 1995. Use of intraopetative corticosteroids in pediatric pediatric tonsillectomy. Arch., Otolaryngol. Head Neck Surg., 121: 737-742.

15. Pemberton CM, Moxness KE, German MJ, Nelson JK, Gastineau CF. Mayo Clinic diet manual: a handbook of dietary practices. BC Decker, Inc.; 1988.

16. Strub KA, Tschopp K, Frei F, Kern C, Erb T. Zur lokalen Infiltration von Epinephrin und Bupivacain vor Tonsillektomie. HNO. 1996 Dec 1;44(12):672-6.

17. Timby BK, Smith NE. Introductory medical-surgical nursing. Lippincott Williams \& Wilkins; 2013 Aug 19.

18. Vasan NR, Stevenson S, Ward M. Preincisional bupivacaine in posttonsillectomy pain relief: a randomized prospective study. Archives of OtolaryngologyHead \& Neck Surgery. 2002 Feb 1;128(2):145-9. 
19. Unal Y, Pampal K, Korkmaz S, Arslan M, Zengin A, Kurtipek O. Comparison of bupivacaine and ropivacaine on postoperative pain after tonsillectomy in pediatric patients. International journal of pediatric otorhinolaryngology. 2007 Jan 1;71(1):83-7. 